\title{
Prevention of ventilator-associated pneumonia in intensive care units: an international online survey
}

Marie-Laurence Lambert ${ }^{*}$, Mercedes Palomar ${ }^{2,3}$, Antonella Agodi ${ }^{4}$, Michael Hiesmayr $^{5}$, Alain Lepape ${ }^{6}$, Anne Ingenbleek ${ }^{1}$, Eduardo Palencia Herrejon ${ }^{7}$, Stijn Blot $^{8}$ and Uwe Frank ${ }^{9}$

\begin{abstract}
Background: On average 7\% of patients admitted to intensive-care units (ICUs) suffer from a potentially preventable ventilator-associated pneumonia (VAP). Our objective was to survey attitudes and practices of ICUs doctors in the field of VAP prevention.

Methods: A questionnaire was made available online in 6 languages from April, $1^{\text {st }}$ to September $1^{\text {st }}, 2012$ and disseminated through international and national ICU societies. We investigated reported practices as regards (1) established clinical guidelines for VAP prevention, and (2) measurement of process and outcomes, under the assumption "if you cannot measure it, you cannot improve it"; as well as attitudes towards the implementation of a measurement system. Weighted estimations for Europe were computed based on countries for which at least 10 completed replies were available, using total country population as a weight. Data from other countries were pooled together. Detailed country-specific results are presented in an online additional file.

Results: A total of 1730 replies were received from 77 countries; 1281 from 16 countries were used to compute weighted European estimates, as follows: care for intubated patients, combined with a measure of compliance to this guideline at least once a year, was reported by $57 \%$ of the respondents ( $95 \% \mathrm{Cl}$ : $54-60$ ) for hand hygiene, $28 \%$ (95\% Cl: 24-33) for systematic daily interruption of sedation and weaning protocol, and 27\% (95\%: 23-30) for oral care with chlorhexidine. Only 20\% (95\% Cl: 17-22) were able to provide an estimation of outcome data (VAP rate) in their ICU, still 93\% (95\% Cl: 91-94) agreed that "Monitoring of VAP-related measures stimulates quality improvement". Results for 449 respondents from 61 countries not included in the European estimates are broadly comparable.
\end{abstract}

Conclusions: This study shows a low compliance with VAP prevention practices, as reported by ICU doctors in Europe and elsewhere, and identifies priorities for improvement.

Keywords: Healthcare associated infection, Ventilator-associated pneumonia, Patient safety, Preventive measures, Quality of care

\footnotetext{
* Correspondence: mllambert@wiv-isp.be

${ }^{1}$ Healthcare associated infections unit, Scientific Institute of Public Health, Rue Juliette Wytsmanstraat 14, Brussels 1050, Belgium

Full list of author information is available at the end of the article
} 


\section{Introduction}

Ventilator-associated pneumonia (VAP) is a frequent and severe health-care associated infection. In Europe, pneumonia occur in $7.0 \%$ of patients staying at least 2 days in intensive care units (ICUs); $91 \%$ of these pneumonia are VAP [1]. The proportion of VAP which is preventable is debated [2] but there is no doubt that a serious potential for harm reduction does exist $[3,4]$ and VAP prevention is becoming a major patient safety issue. In the US for instance, VAP prevention has been proposed as a national safety goal [2].

VAP prevention requires clinical interventions (best practice guidelines) combined with non clinical interventions to ensure implementation and compliance with these guidelines.

Clinical interventions for VAP prevention fall in three categories [5]. The first, obvious one, is to limit exposure to mechanical ventilation by preferring non-mechanical ventilation when possible and limiting its duration when alternative options are not possible. Other prevention practices aim at reducing airways colonization (such as oral care decontamination using chlorhexidine [6]), or preventing aspiration [5] (e.g. by nursing in the semirecumbent position, or maintaining a sufficient cuff pressure). Clinical interventions should be combined, in what is often called a "care bundle". The precise content of VAP care bundle varies between guidelines $[7,8]$ because the number of items in a "bundle" should be limited, some prevention practices are controversial (e.g. selective digestive decontamination), [9] and recommending best practice regarding such measures requires compromise and pragmatism [8]. There is no universally accepted "VAP care bundle". A study aiming at defining a "European care bundle" ranked VAP prevention measures by combining criteria such as the strength of the supporting evidence, ease of implementation, and expected impact [10]. The top 5 clinical interventions (we did not consider "trained staff" as a clinical intervention) were: 1 ) no ventilatory circuit change unless specifically indicated; 2) strict hand hygiene with alcohol especially before managing the airways; 3 ) daily sedation vacation and weaning protocol; 4) oral care with chlorhexidine; and 5) cuff pressure control at least every 24 hrs. It was beyond the scope of our study to assess the evidence behind each of these interventions, but none appears to be controversial.

Ensuring compliance with guidelines is a vast and complex field of research [11-13]. Common to any improvement strategy is the need for measurement; this serves evaluation purposes, measurement can also be the intervention, or a major component of it [14-16]. In a survey on infection control practices in the US, ICUs were only able to reduce heathcare-associated infection rates (including VAP), when they had a written policy, monitored compliance, and achieved a $\geq 95 \%$ compliance to all elements included in the local care bundle [11,17]. Under the unchallenged assumption "if you cannot measure it, you cannot improve it" (Lord Kelvin, 1824-1907), we considered here that monitoring process (compliance to guidelines) and outcomes is a necessary, if not sufficient, component of any intervention aiming at decreasing VAP.

Accurate diagnosis of VAP is a challenge, because many conditions commonly encountered in critically ill patients - such as pulmonary oedema, pulmonary hemorrhage and acute respiratory distress syndrome, can mimic the signs and symptoms of pneumonia [5]. Clinical diagnosis leads to treatment decisions, its primary aim is to be accurate, and it cannot be entirely standardized. By contrast measurement need primarily to be reproducible to ensure comparability of data overtime and allow evaluation of trends. Standardization is essential. Criteria for diagnosis and criteria for recording, therefore do not necessarily overlap entirely. Guidelines and definitions of VAP for recording and reporting exist in Europe [18] and in the United States [19]. Despite some changes in the US, current case-definitions are still considered useful for internal quality improvement purposes [20].

Our objectives were to document, using a web-based survey (1) reported VAP prevention practices in ICUs (clinical practices, and measurement) and (2) attitudes towards the implementation of a measurement system. Our primary interest laid in providing estimates at European level, but we did not define exclusion criteria based on geographical location; on the other hand country-specific results can be used to steer prevention initiatives at country level.

\section{Methods}

\section{Study population}

Our target group was physicians working in ICUs. An ICU was defined as an unit meeting all the following criteria: provides facilities for invasive mechanical ventilation, and pump-controlled administration of infusion, functions 24 hours a day and 7 days a week, and there is at least one doctor immediately available at all times to deal with emergencies.

\section{Questionnaire}

We developed a questionnaire with 3 parts: 1) Characteristics of the respondent and her/his ICU, 2) VAP prevention practices (clinical, and measurement). For clinical practices we focused on the top 5 clinical components of the European VAP care bundle [10] and added a commonly recommended practice (head of bed elevation) [5]. For measurement, we included questions on measurement of process (compliance to prevention 
practices, average duration of intubation) and outcomes (measurement of VAP, definitions used for data collection - European, [18] or American, [19] and the ability to report selected indicators. 3) attitudes as regards the implementation of a data collection system, using a 5 point-Likert scale (1: strongly agree, 5: strongly disagree) $[13,21]$. The questionnaire was kept very short to improve participation. It was first developed and pre-tested in English, then translated into German, Italian, Spanish, Portuguese and French by intensive care doctors and/or infection control practitioners, native speakers in the targeted language. Each translation had to be independently checked by at least another native speaker doctor. We used Limesurvey 2.0, an open source web survey application, to collect the data [22]. Participation was anonymous.

\section{Dissemination to target group}

The questionnaire was available online from April 1 to September 1, 2012. It was endorsed by the European Society of Intensive Care Medicine (ESICM), posted on their website, and the link e-mailed to all its members. We contacted national ESICM representatives and key opinion leaders and requested their support in disseminating the survey in their country. The survey was endorsed by national ICU societies in Austria, France, Belgium, the Netherlands, Italy, and Greece. It was e-mailed to all subscribers of REMI (Revista Electronica de Medicina Intensiva), [23] an electronic newsletter on intensive care medicine in Spanish distributed in Spain, Portugal, and Latin America.

\section{Data analysis}

Descriptive statistics were used to characterize the study sample. Using total country population (2012 United Nations estimates [24]) as the weight, we computed weighted European estimates including all countries which provided at least 10 completed replies. This arbitrary threshold was chosen as a compromise between the number of countries included in the European estimates, and precision of the estimation. Statistical software STATA 10 was used for the analyses (svy command for survey data for weighted estimates). Replies from the remaining countries, both European and non European, were simply pooled together. We choose to present uncommented, detailed country-specific results as Additional file 1, for use by national stakeholders.

\section{Results}

A total of 1730 completed replies from 77 different countries were submitted (Table 1). Characteristics of the respondents, and their setting, are presented in Table 2.
Table 1 Number of replies to the survey, by country

\begin{tabular}{|c|c|c|}
\hline & Replies & $\%$ \\
\hline \multicolumn{3}{|l|}{ European countries } \\
\hline Spain & 293 & $17 \%$ \\
\hline France & 251 & $15 \%$ \\
\hline Italy & 187 & $11 \%$ \\
\hline Austria & 130 & $8 \%$ \\
\hline United Kingdom & 115 & $7 \%$ \\
\hline Germany & 67 & $4 \%$ \\
\hline Portugal & 50 & $3 \%$ \\
\hline Belgium & 33 & $2 \%$ \\
\hline Netherlands & 31 & $2 \%$ \\
\hline Switzerland & 29 & $2 \%$ \\
\hline Greece & 23 & $1 \%$ \\
\hline Romania & 20 & $1 \%$ \\
\hline Denmark & 15 & $1 \%$ \\
\hline Sweden & 14 & $1 \%$ \\
\hline Ireland & 13 & $1 \%$ \\
\hline Hungary & 10 & $1 \%$ \\
\hline Total European countries with at least 10 replies* & 1281 & $74 \%$ \\
\hline Other (18 different countries) & 55 & $3 \%$ \\
\hline \multicolumn{3}{|l|}{ Non European countries } \\
\hline India & 63 & $4 \%$ \\
\hline Argentina & 40 & $2 \%$ \\
\hline Colombia & 31 & $2 \%$ \\
\hline Mexico & 31 & $2 \%$ \\
\hline Australia & 23 & $1 \%$ \\
\hline Peru & 23 & $1 \%$ \\
\hline Brazil & 21 & $1 \%$ \\
\hline Ecuador & 13 & $1 \%$ \\
\hline Chile & 12 & $1 \%$ \\
\hline Turkey** & 12 & $1 \%$ \\
\hline United States & 12 & $1 \%$ \\
\hline Saudi Arabia & 11 & $1 \%$ \\
\hline United Arab Emirates & 11 & $1 \%$ \\
\hline Venezuela & 11 & $1 \%$ \\
\hline Other (29 different countries) & 80 & $5 \%$ \\
\hline Survey - total & 1730 & $100 \%$ \\
\hline
\end{tabular}

* Used for European weighted estimates.

** Considered as non European as majority of population does not live in Europe.

Weighted European estimates are based on 1281 respondents from the 16 countries from which at least 10 completed replies were available.

VAP prevention practices are presented in Table 3 (clinical practices) and Table 4 (measurements). 
Table 2 Characteristics of the respondents, and of their setting

\begin{tabular}{|c|c|c|c|c|c|c|c|}
\hline \multirow[t]{2}{*}{ Respondent } & \multicolumn{3}{|c|}{$\begin{array}{l}\text { Weighted estimates for } \\
\text { Europe (respondents from } 16 \\
\text { countries with }>=10 \text { replies) }\end{array}$} & \multicolumn{4}{|c|}{$\begin{array}{l}\text { Other respondents (61 } \\
\text { countries) }\end{array}$} \\
\hline & \multirow{2}{*}{$\begin{array}{c}\mathbf{N}=\mathbf{1 2 8 1} \\
12.8\end{array}$} & \multicolumn{2}{|c|}{$95 \% \mathrm{Cl}$} & \multicolumn{2}{|c|}{$\mathrm{N}=449$} & \multicolumn{2}{|c|}{$95 \% \mathrm{Cl}$} \\
\hline Years working in ICU (mean) & & 12.2 & 13.3 & & & 12.1 & 13.6 \\
\hline Admissions per year in their ICU (mean) & 1006 & 914 & 1098 & & & 787 & 1013 \\
\hline $\mathrm{N}$ beds in ICU (mean) & 16 & 15 & 17 & & & 15.4 & 17.3 \\
\hline & $\%^{*}$ & & & $N$ & $\%$ & & \\
\hline Gender (females) & 28 & 25 & 31 & 82 & 18 & 15 & 22 \\
\hline Working in hospital with $>1000$ beds & 17 & 14 & 20 & 18 & 4 & 2 & 6 \\
\hline Working in hospital with $300-1000$ beds & 55 & 52 & 56 & 145 & 33 & 28 & 37 \\
\hline Working in hospital $<300$ beds & 28 & 26 & 31 & 282 & 63 & 58 & 67 \\
\hline
\end{tabular}

* Absolute numbers are not reported because percentages are weighted estimates.

Attitudes towards the implementation of a VAP measurement system are presented in Table 5 .

\section{Discussion}

\section{Key results}

This is, to our knowledge, the first international survey assessing VAP prevention practices - (clinical, and measurement) - among ICUs doctors. Participation was large, and almost two thirds of respondents reported the existence of written VAP prevention guidelines in their ICU - pointing out the interest in, and awareness of the problem. If we combine the good clinical practice, AND measuring compliance to this practice at least once a year (a very pragmatic objective), this was reported by
57\% (hand hygiene), 29\% (daily interruption of sedation) and $26 \%$ (oral care with chlorhexidine) of the participants to this survey (European estimates). Interestingly, "head of bed elevation" - a practice ranked very low in the "European care bundle" because it was perceived as difficult to implement - was mentioned by $96 \%$ of the respondents; this clinical practice was known by $85 \%$ of European nurses participating in a knowledge test about VAP prevention practices [25].

As regards measurement of outcomes, European estimates show that only $54 \%$ count and record the number of VAP on a routine basis; and only $20 \%$ were able to provide data for their ICU on the main indicator used to monitor VAP - (VAP/1000 intubation-days). In contrast

Table 3 VAP prevention: clinical practices, as reported by ICU doctors

\begin{tabular}{|c|c|c|c|c|c|c|c|}
\hline \multirow[t]{3}{*}{ Clinical practice } & \multirow{2}{*}{\multicolumn{3}{|c|}{$\begin{array}{c}\text { Weighted } \\
\text { estimates for } \\
\text { Europe } \\
\text { (respondents from } \\
16 \text { countries with } \\
\text { >=10 replies) } \\
\mathrm{N}=1281\end{array}$}} & \multicolumn{4}{|c|}{$\begin{array}{l}\text { Other respondents ( } 61 \\
\text { countries) }\end{array}$} \\
\hline & & & & \multicolumn{4}{|c|}{$\mathrm{N}=449$} \\
\hline & \%* & \multicolumn{2}{|c|}{$95 \% \mathrm{Cl}$} & \multirow{2}{*}{$\begin{array}{c}\mathbf{N} \\
395\end{array}$} & $\%$ & & \\
\hline $\begin{array}{l}\text { In my ICU, hand hygiene is done with alcohol hand rub, always, } \\
\text { or most of the time }\end{array}$ & 95 & 94 & 97 & & 88 & 85 & 91 \\
\hline In my ICU, there are written guidelines for VAP prevention & 65 & 62 & 69 & 282 & 63 & 58 & 67 \\
\hline Guidelines developed locally & 33 & 30 & 36 & 162 & 36 & 32 & 41 \\
\hline Guidelines developed nationally & 31 & 28 & 34 & 117 & 26 & 22 & 30 \\
\hline In my ICU, care for intubated patients includes... & & & & & & & \\
\hline No ventilatory circuit changes unless specifically indicated & 69 & 66 & 72 & 371 & 83 & 79 & 86 \\
\hline Strict hand hygiene using alcohol, especially before managing the airways & 83 & 80 & 86 & 364 & 81 & 77 & 85 \\
\hline Systematic daily interruption of sedation and weaning protocol & 49 & 46 & 53 & 285 & 63 & 59 & 68 \\
\hline Oral care with chlorhexidine & 70 & 67 & 73 & 302 & 67 & 63 & 72 \\
\hline Cuff pressure control at least every 24 hours & 83 & 81 & 85 & 347 & 77 & 73 & 81 \\
\hline Head of bed elevation & 96 & 94 & 97 & 442 & 98 & 97 & 100 \\
\hline
\end{tabular}

* Absolute numbers are not reported because percentages are weighted estimates. 
Table 4 VAP prevention: measurements, as reported by ICU doctors

\begin{tabular}{|c|c|c|c|c|c|c|c|}
\hline \multirow[t]{3}{*}{ Measurements } & \multirow{2}{*}{\multicolumn{3}{|c|}{$\begin{array}{l}\text { Weighted estimates for } \\
\text { Europe (respondents } \\
\text { from } 16 \text { countries with } \\
>=10 \text { replies) } \\
\mathrm{N}=1281\end{array}$}} & \multicolumn{4}{|c|}{$\begin{array}{l}\text { Other respondents ( } 61 \\
\text { countries) }\end{array}$} \\
\hline & & & & \multicolumn{4}{|c|}{$N=449$} \\
\hline & \%* & \multicolumn{2}{|c|}{$95 \% \mathrm{Cl}$} & $\mathrm{N}$ & $\%$ & \multicolumn{2}{|c|}{$95 \% \mathrm{Cl}$} \\
\hline Hand hygiene recommendations & 57 & 54 & 60 & 265 & 60 & 54 & 64 \\
\hline Systematic daily interruption of sedation and weaning protocol & 28 & 24 & 33 & 102 & 23 & 19 & 27 \\
\hline Oral care with chlorhexidine & 27 & 23 & 30 & 126 & 28 & 24 & 32 \\
\hline "In my ICU, there is a written definition of VAP for data collection" & 50 & 47 & 54 & 286 & 64 & 59 & 68 \\
\hline YES- European guidelines & 26 & 23 & 29 & 37 & 8 & 6 & 11 \\
\hline YES- CDC guidelines & 12 & 10 & 15 & 206 & 46 & 41 & 51 \\
\hline \multicolumn{8}{|l|}{ "In my ICU, we count and record, routinely..." (\% saying "yes") } \\
\hline VAP & 55 & 51 & 58 & 287 & 64 & 59 & 68 \\
\hline Intubation-days & 81 & 78 & 84 & 364 & 81 & 74 & 85 \\
\hline Intubated patients & 90 & 88 & 92 & 367 & 82 & 78 & 85 \\
\hline \multicolumn{8}{|l|}{$\begin{array}{l}\text { Please provide, if possible, the following data for your ICU - for part or all } 2011 \\
\text { (\% providing data) }\end{array}$} \\
\hline VAP/ 1000 ventilation-days & 20 & 17 & 22 & 113 & 25 & 21 & 29 \\
\hline Mean duration of intubation for intubated patients (days) & 27 & 25 & 30 & 148 & 33 & 29 & 37 \\
\hline Proportion of intubated patients & 38 & 35 & 41 & 178 & 40 & 35 & 44 \\
\hline $\begin{array}{l}\text { "Clinical staff in my ICU is aware of VAP-related measures, } \\
\text { and their trends" (\% agree strongly / agree) }\end{array}$ & 53 & 50 & 56 & 298 & 66 & 62 & 71 \\
\hline
\end{tabular}

* Absolute numbers are not reported because percentages are weighted estimates.

Table 5 Attitudes towards the implementation of a measurement system of infections in ICUs

\begin{tabular}{|c|c|c|c|c|c|c|c|c|c|c|c|c|}
\hline & \multirow{2}{*}{\multicolumn{6}{|c|}{$\begin{array}{l}\text { Weighted estimates for Europe } \\
\text { (respondents from } 16 \text { countries with } \\
>=10 \text { replies) } \\
N=1281\end{array}$}} & \multirow{2}{*}{\multicolumn{6}{|c|}{ Other respondants (66 countries) }} \\
\hline & & & & & & & & & & & & \\
\hline & \multicolumn{3}{|c|}{$\begin{array}{l}\text { Agree strongly/ } \\
\text { agree }\end{array}$} & \multicolumn{3}{|c|}{$\begin{array}{l}\text { Disagree/ disagree } \\
\text { strongly }\end{array}$} & \multicolumn{3}{|c|}{$\begin{array}{l}\text { Agree strongly/ } \\
\text { agree }\end{array}$} & \multicolumn{3}{|c|}{$\begin{array}{c}\text { Disagree/ } \\
\text { disagree strongly }\end{array}$} \\
\hline & $\%$ & $95 \% \mathrm{Cl}$ & $\%$ & $95 \% \mathrm{Cl}$ & $\%$ & $95 \% \mathrm{Cl}$ & $\%$ & $95 \% \mathrm{Cl}$ & & & & \\
\hline \multicolumn{13}{|l|}{ To what extent do you agree with the following comments } \\
\hline If you cannot measure it, you cannot improve it & 83 & 80 & 85 & 11 & 9 & 13 & 84 & 80 & 87 & 11 & 8 & 14 \\
\hline Monitoring of VAP related measures stimulates quality improvement & 93 & 91 & 94 & 2 & 1 & 3 & 97 & 94 & 98 & 1 & 0 & 3 \\
\hline VAP-related measures in my ICU (if any) are reliable & 54 & 51 & 58 & 12 & 10 & 15 & 66 & 61 & 70 & 8 & 6 & 11 \\
\hline I am willing to implement, or support, a VAP data collection system & 84 & 81 & 86 & 4 & 3 & 6 & 92 & 89 & 94 & 1 & 0 & 3 \\
\hline $\begin{array}{r}\text { Clinical diagnosis of VAP is difficult: this makes measurement } \\
\text { systems unreliable }\end{array}$ & 46 & 43 & 50 & 32 & 29 & 36 & 43 & 38 & 47 & 36 & 32 & 41 \\
\hline $\begin{array}{r}\text { There is a difference between a definition of VAP for reporting, } \\
\text { and a diagnosis of VAP for treatment }\end{array}$ & 45 & 42 & 49 & 32 & 28 & 35 & 46 & 41 & 50 & 30 & 26 & 35 \\
\hline \multicolumn{13}{|c|}{ Please indicate what actions would facilitate the implementation of a measurement system of infections in ICUs } \\
\hline Timely feed-back of data at ICU level & 92 & 90 & 94 & 1 & 1 & 2 & 96 & 93 & 97 & 0 & 0 & 2 \\
\hline Administrative support & 88 & 86 & 90 & 2 & 1 & 3 & 95 & 92 & 97 & 1 & 0 & 2 \\
\hline Dedicated software / IT resources & 91 & 89 & 93 & 2 & 1 & 3 & 92 & 89 & 94 & 0 & 0 & 2 \\
\hline Reliable data & 95 & 93 & 96 & 1 & 0 & 2 & 96 & 94 & 98 & 0 & 0 & 1 \\
\hline
\end{tabular}


with these low proportions 93\% agreed that "monitoring of VAP-related measures stimulates quality improvement" and $84 \%$ said they were willing to implement, or support, a VAP data collection system. They expressed some distrust as regards the data $(46 \%$ agreed with the statement "clinical diagnosis of VAP is difficult; this makes measurement unreliable"), on the other hand, only $50 \%$ were aware of a standardized case definition for VAP recording in their ICU; and only $45 \%$ understood the difference between a definition of VAP for recording, and a diagnosis of VAP. Overall, 95\% of respondents agreed that reliable data would facilitate the implementation of a measurement system.

These European estimates mask large difference between countries. For example oral care with chlorhexidine was reported by $55 \%(139 / 251)$ of the respondents in France, and by 94\% (276/293) in Spain. Respondents saying yes to the question "in my ICU, we count and record VAP on a routine basis" were 50\% (57/115) in the UK, and 74\% (218/293) in Spain. Daily sedation vacation and weaning protocol were reported by $81 \%$ (93/115) in the UK, and by $35 \%(66 / 187)$ in Italy (see countryspecific data, as Additional file 1).

Results from the 449 respondents not included in the European estimates are surprisingly similar to those of the European estimates.

\section{Strengths and Limitations}

This survey has several limitations. First, we cannot claim that participants represent a random sample of ICU clinicians in Europe nor in their own country. Some categories of ICU doctors are likely to be overrepresented, such as members of ICU national, or international societies. These might be better informed, and apply VAP prevention guidelines more than the average clinician. The list of VAP prevention measures we used as a reference for good practices guidelines [10] could be criticized on several grounds, e.g. it does not include subglottic secretions drainage [26]. Our dissemination strategy obviously worked better in some countries than others. Another limitation is that some questions in the questionnaire apply to the individual physician and others to the ICU ("in my ICU, care for intubated patients includes...) but the online questionnaire did not include questions allowing for the identification of the ICU, in order to preserve the anonymity of the respondents.

Respondents not included in the European estimates represent a very heterogeneous population with no clear geographical basis. We nevertheless considered it worthwhile to pool these results, because together these doctors are responsible for a large number of patients, and these data have identified weaknesses broadly similar to those observed in the European estimates.
Clearly, it cannot be concluded from a doctor's reporting of a clinical practice in her/his setting, that this practice is used all the time for every patient who needs it: self-reports mainly provide information regarding clinicians' knowledge of guideline recommendations, but they are subject to bias - overestimation - and should not be used as the sole measure of guideline adherence [27]. Measuring compliance to guidelines at local level once a year appears as an absolute minimum. We did not ask details on the methods used to measure compliance. This is not necessarily easy, for instance detailed guidelines exist for measuring compliance to hand hygiene recommendations; [28] and oral care in ventilated patients is a complex procedure that might require a check list [29].

It was not among the objectives of this survey to collect data on VAP incidence rate in ICUs - there are much better sources for this - e.g. surveillance data for Europe [1]. Rather we wanted to investigate the knowledge doctors had of the rates in their units. However data provided on VAP rates (not shown) are in the expected range as reported in surveillance networks [1], giving some validity to our results.

\section{Interpretation}

The large participation to this survey reflects the interest of the ICU community in the issue of VAP prevention. To the extent that the selection bias, and the reporting bias in our results lead to overestimating VAP prevention practices in ICUs, weaknesses identified appear robust enough as to support targeted interventions for improvement. The priority for improving care of intubated patients is promoting the clinical practices with the lowest reported use (daily sedation vacation, and weaning protocols, oral care with chlorhexidine, and no ventilatory circuit change unless specifically indicated). Improving knowledge of clinical guidelines is far from sufficient to improve practices $[25,30]$ but it is a prerequisite. ICUs doctors overwhelmingly agree that monitoring of VAP-related measures stimulates quality improvement but very few do it, although most are willing to do it. They could be helped to do so by learning how to produce reliable data (standardized case-definitions, methods for measuring compliance) with realtime feed-back at the ICU level; so that clinical staff could monitor their own trends over time. A compromise needs to be found between time-consuming data collection, and usefulness of data. Additional resources (human resources, information technology) might help, but some very simple measures can be implemented with minimal input, e.g. in some ICUs a panel with the number of days since last ICU-acquired infection (including VAP) is displayed on the board and updated 
daily (personal observations in Scotland, MLL). This study did not consider the issue of surveillance and reporting of outcome indicators at regional or national level, nor the merits (or otherwise) of evaluation of performance and feed-back, based on benchmarking (e.g. comparisons between units). Specific priorities might differ between countries.

\section{Conclusions}

This survey has documented a large potential for improvement in clinical and non-clinical practices aimed at preventing VAP in ICUs. Some results, such as a large agreement of the respondents that data collection is essential - "if you cannot measure it, you cannot improve it" - extend beyond the issue of VAP prevention. Promoting the implementation of guidelines for VAP prevention needs to be done together with promoting the measurement of compliance to these guidelines and measurement of outcomes as a tool for improvement, keeping data collection systems at ICU level as simple as possible: what is important is usefulness, not perfection [31].

\section{Additional file}

\section{Additional file 1: Detailed country-specific results: number} responding, respondents characteristics, reported practices, attitudes.

\section{Competing interest}

The authors declare that they have no competing interests.

\section{Authors' contributions}

MLL, MP, AA, MH and UF designed the study. MLL and Al collected and analyzed the data. MLL wrote the first draft of the article. MP, $A A, M H, A L, S B$, $\mathrm{Al}$ and $\mathrm{EPH}$ revised the report. All authors saw and approved the final report.

\section{Acknowledgments}

We are grateful to the following collaborating partners for their contribution to the project: Afonso Elsa, Antonelli Massimo, Aragao Irene, Brun-Buisson Christian, Cardoso Teresa, Catry Boudewijn, Cunha Andreia, De Boom Dominique, François Guy, Hoste Eric, Kaier Klaus, Koulenti Despoina, Mura Ida, Muzlovic Igor, Popa Mircea Ioan, Preiser Charles, Rello Jordi, Savey Anne, Schouten Jeroen, Stevens Alan, Tamowicz Barbara, Via Gabriele, Zapletal Bernhard.

\section{Data sharing}

Data are freely available and have been deposited in the Dryad Digital Repository http://datadryad.org doi:10.5061/dryad.q1d7f Further use and exploitation of these data is encouraged.

\section{Funding}

This study was supported by the European Commission (Project IMPLEMENT, commissioned by Directorate General for Health and Consumer Protection (DG SANCO), Grant Agreement № 2009-11-07; (http://www.eu-implement.info). The funding source had no role in the study design, collection, analysis, and interpretation of data, nor in the decision to submit the manuscript.

\section{Author details}

${ }^{1}$ Healthcare associated infections unit, Scientific Institute of Public Health, Rue Juliette Wytsmanstraat 14, Brussels 1050, Belgium. ${ }^{2}$ Intensive care department, Hospital Vall d'Hebron, Barcelona, Spain. ${ }^{3}$ Universitat Autonoma de Barcelona, Barcelona, Spain. ${ }^{4}$ Department GF Ingrassia, University of Catania, Catania, Italy. ${ }^{5}$ Department Anaesthesia, General Intensive Care and Pain Control, Medical University of Vienna, Vienna, Austria. ${ }^{6}$ Department Anaesthesia, General Intensive Care, University hospital, Lyon, France. 7Intensive Care department, Hospital Universitario "Infanta Leonor", Madrid, Spain. ${ }^{8}$ Department of Internal Medicine, Ghent University, De Pintelaan 185, Ghent 9000, Belgium. 'Infectious diseases department, University hospital, Heidelberg, Germany.

Received: 25 January 2013 Accepted: 7 March 2013

Published: 26 March 2013

\section{References}

1. European Centre for Disease Prevention and Control: Surveillance of health-care associated infections in Europe 2007. Report. Stockholm: ECDC; 2012. http://ecdc.europa.eu/en/publications/Publications/120215_SUR_ HAl_2007.pdf.

2. Klompas $\mathrm{M}$ : Is a ventilator-associated pneumonia rate of zero really possible? Curr Opin Infect Dis 2012, 25:176-182.

3. Berenholtz SM, Pham JC, Thompson DA, Needham DM, Lubomski LH, Hyzy RC, Welsh R, Cosgrove SE, Sexton JB, Colantuoni E, et al: Collaborative cohort study of an intervention to reduce ventilator-associated pneumonia in the intensive care unit. Infect Control Hosp Epidemiol 2011, 32:305-314.

4. Gastmeier P, Geffers C: Prevention of ventilator-associated pneumonia: analysis of studies published since 2004. J Hosp Infect 2007, 67:1-8.

5. Hunter JD: Ventilator associated pneumonia. BMJ 2012, 344:e3325.

6. Labeau SO, Van de Vyver K, Brusselaers N, Vogelaers D, Blot SI: Prevention of ventilator-associated pneumonia with oral antiseptics: a systematic review and meta-analysis. Lancet Infect Dis 2011, 11:845-854.

7. Institute for Health Care Improvement: Implement the IHI Ventilator Bundle. Boston, USA: Institute for Health Care Improvement (IHI); 2012. http://www. ihi.org/knowledge/pages/changes/implementtheventilatorbundle.aspx.

8. Scottish Intensive Care Society Audit Group: VAP prevention bundle: guidance for implementation. National Health Services Scotland; 2008. http://www.vap. kchealthcare.com/media/132767/vap\%20prevention\%20bundle\%20-\% 20scottish\%20intensive\%20care\%20society\%20audit\%20group.pdf.

9. Lorente $L$, Blot $S$, Rello J: Evidence on measures for the prevention of ventilator-associated pneumonia. Eur Respir J 2007, 30:1193-1207.

10. Rello J, Lode H, Cornaglia G, Masterton R: A European care bundle for prevention of ventilator-associated pneumonia. Intensive Care Med 2010, 36:773-780.

11. Pogorzelska M, Stone PW, Furuya EY, Perencevich EN, Larson EL, Goldmann D, Dick A: Impact of the ventilator bundle on ventilator-associated pneumonia in intensive care unit. Int J Qual Health Care 2011, 23:538-544.

12. Pronovost PJ, Berenholtz SM, Needham DM: Translating evidence into practice: a model for large scale knowledge translation. BMJ 2008, 337:a1714.

13. Cabana MD, Rand CS, Powe NR, Wu AW, Wilson MH, Abboud PA, Rubin HR: Why don't physicians follow clinical practice guidelines? a framework for improvement. JAMA 1999, 282:1458-1465.

14. Pronovost PJ, Goeschel CA, Colantuoni E, Watson S, Lubomski LH, Berenholtz SM, Thompson DA, Sinopoli DJ, Cosgrove S, Sexton JB, et al: Sustaining reductions in catheter related bloodstream infections in Michigan intensive care units: observational study. BMJ 2010, 340:c309.

15. Cole A: Reporting scheme leads to cut in central line infection rates. BMJ 2010, 341:C6861.

16. Scales DC, Dainty K, Hales B, Pinto R, Fowler RA, Adhikari NK, Zwarenstein $\mathrm{M}$ : A multifaceted intervention for quality improvement in a network of intensive care units: a cluster randomized trial. JAMA 2011, 305:363-372.

17. Furuya EY, Dick A, Perencevich EN, Pogorzelska M, Goldmann D, Stone PW Central line bundle implementation in US intensive care units and impact on bloodstream infections. PLoS One 2011, 6:e15452.

18. European Centre for Disease Prevention and Control: European surveillance of healthcare-associated infections in intensive care units. HAllCU protocol v1.01-Standard and light. ECDC; 2010. http://www.ecdc.europa.eu/en/ aboutus/calls/Procurement\%20Related\%20Documents/ 5_ECDC_HAllCU_protocol_v1_1.pdf. 
19. Horan TC, Andrus M, Dudeck MA: CDC/NHSN surveillance definition of health care-associated infection and criteria for specific types of infections in the acute care setting. Am J Infect Control 2008, 36:309-332.

20. Centers for Disease Control and Prevention - Division for Health Care Quality Promotion: Improving Surveillance for Ventilator-Associated Events in Adults. CDC; 2012. http://www.cdc.gov/nhsn/PDFs/vae/CDC_VAE_ CommunicationsSummary-for-compliance_20120313.pdf.

21. de Vos ML, van der Veer SN, Graafmans WC, de Keizer NF, Jager K, Wester $G$, van der Voort PH: Implementing quality indicators in intensive care units: exploring barriers to and facilitators of behaviour change. Implement Sci 2010, 5:52

22. Computer program: Limesurvey: an open source survey application. http://www.limesurvey.org/.

23. REMI: Revista electronica de medicina intensiva. http://remi.uninet.edu/.

24. List of European countries by population (United Nations 2012 estimates). http://en.wikipedia.org/wiki/List_of_European_countries_by_population.

25. Labeau S, Vandijck D, Rello J, Adam S, Rosa A, Wenisch C, Backman C, Agbaht K, Csomos A, Seha M, et al: Evidence-based guidelines for the prevention of ventilator-associated pneumonia: results of a knowledge test among European intensive care nurses. J Hosp Infect 2008, 70:180-185.

26. Muscedere J, Rewa O, McKechnie K, Jiang X, Laporta D, Heyland DK: Subglottic secretion drainage for the prevention of ventilator-associated pneumonia: a systematic review and meta-analysis. Crit Care Med 2011, 39:1985-1991

27. Adams AS, Soumerai SB, Lomas J, Ross-Degnan D: Evidence of self-report bias in assessing adherence to guidelines. Int J Qual Health Care 1999, 11:187-192.

28. Sax H, Allegranzi B, Chraiti MN, Boyce J, Larson E, Pittet D: The world health organization hand hygiene observation method. Am J Infect Control 2009, 37:827-834.

29. Cutler CJ, Davis N: Improving oral care in patients receiving mechanical ventilation. Am J Crit Care 2005, 14:389-394.

30. Rello J, Lorente C, Bodi M, Diaz E, Ricart M, Kollef MH: Why do physicians not follow evidence-based guidelines for preventing ventilatorassociated pneumonia? a survey based on the opinions of an international panel of intensivists. Chest 2002, 122:656-661.

31. Nelson EC, Splaine ME, Batalden PB, Plume SK: Building measurement and data collection into medical practice. Ann Intern Med 1998, 128:460-466.

doi:10.1186/2047-2994-2-9

Cite this article as: Lambert et al:: Prevention of ventilator-associated pneumonia in intensive care units: an international online survey. Antimicrobial Resistance and Infection Control 2013 2:9.

\section{Submit your next manuscript to BioMed Central and take full advantage of:}

- Convenient online submission

- Thorough peer review

- No space constraints or color figure charges

- Immediate publication on acceptance

- Inclusion in PubMed, CAS, Scopus and Google Scholar

- Research which is freely available for redistribution

Submit your manuscript at www.biomedcentral.com/submit 